\title{
Determination of Hexanal as an Oxidative Marker in Vegetable Oils Using an Automated Dynamic Headspace Sampler Coupled to a Gas Chromatograph/Mass Spectrometer"
}

\author{
Jaeho Ha, ${ }^{* \dagger}$ Dong-Won Seo, ${ }^{*}$ Xi Chen, ${ }^{* *}, * * *$ Jin-Bong Hwang, ${ }^{*}$ and You-Shin ShIM* \\ *Food Analysis Center, Korea Food Research Institute, 516, Baekhyeon, Bundang, Seongnam, Gyeonggi, \\ 463-746, Republic of Korea \\ **Department of Chemistry and the Key Laboratory of Analytical Sciences of the Ministry of Education, \\ College of Chemistry and Chemical Engineering, Xiamen University, Xiamen 361005, China \\ ***State Key Laboratory of Marine Environmental Science, Xiamen University, Xiamen 361005, China
}

\begin{abstract}
An automated dynamic headspace sampler coupled to a gas chromatograph/mass spectrometer was evaluated as an oxidative marker to determine hexanal content in vegetable oils. For the effective analysis, a cooled injection system (CIS) was used to focus and to introduce the hexanal desorbed from the Tenax TA. The temperature of the CIS was maintained at $-60^{\circ} \mathrm{C}$ for $12 \mathrm{~min}$ before desorbing the hexanal. Hexanal was separated on a capillary column (DB-5, $0.25 \mathrm{~mm} \times 60 \mathrm{~m}, 0.25 \mu \mathrm{m}$ in film thickness) from 50 to $230^{\circ} \mathrm{C}$, followed by mass spectrometer-selected ion monitoring analysis at $\mathrm{m} / \mathrm{z}$ 56. The instrumental response to hexanal was highly linear from $10 \mathrm{ng} \mathrm{mL}^{-1}$ to $1 \mu \mathrm{g} \mathrm{mL}-1$ $\left(r^{2}=0.9999\right)$. The relative standard deviation (RSD) of intra- and inter-day repeatability was acceptable, with values of less than 3.88 and $4.25 \%$, respectively. The LOD and LOQ of hexanal were determined by gas chromatograph/mass spectrometer-selected ion monitoring to be 3.3 and $9.8 \mathrm{ng} \mathrm{mL}^{-1}$, respectively. The acid value, peroxide value and fatty acid composition revealed a good correlation with the hexanal concentration.
\end{abstract}

(Received November 29, 2010; Accepted March 29, 2011; Published September 10, 2011)

\section{Introduction}

Lipids provide one of the highest sources of energy in food and also play roles in determining the overall physical characteristics of food, including flavor, texture, mouth feel and appearance. Lipids composed of fatty acids can be oxidized during processing and storage at room temperature in the presence of oxygen due to the presence of unsaturated carbon-carbon bonds. Much research has been performed on the mechanism of lipid oxidation, as a quality indicator of lipids including vegetable oils. ${ }^{1-4}$ For the assessment of lipid oxidation of vegetable oils, there are several indicators; including acid value (AV), peroxide value (POV), anisidine value and thiobarbituric acid value. To date, none of these parameters can be used alone to determine lipid oxidation. ${ }^{5,6}$ It was reported that certain aldehydes, ketones and other compounds could be markers for oil and fat oxidation, of which hexanal was reported to be an alternative marker for lipid oxidation..$^{7-9}$

Hexanal content is directly related to oxidative off-flavors, and the compound is easily detected because of its low odor threshold $\left(5 \mathrm{ng} \mathrm{g}^{-1}\right) .{ }^{10,11}$ However, hexanal has the potential to react further, and it is not always possible to measure the compound directly. Although direct injection of the lipid

" Presented at 2010 China-Japan-Korea Symposium on Analytical Chemistry.

† To whom correspondence should be addressed.

E-mail: jhkfri@kfri.re.kr fraction into a gas chromatograph (GC) instument has been used, different sampling techniques have been evaluated to isolate and concentrate volatile compounds prior to GC injection, including solid phase extraction (SPE), simultaneous steam distillation, liquid extraction and headspace (HS) analysis. ${ }^{12,13}$

Static headspace gas chromatograph/mass spectrometer (GC/MS) analysis is generally not sensitive enough to determine the markers for oil and fat oxidation at the levels required. Gas phase/solid phase microextraction (SPME) provides better sensitivity and is used widely for monitoring purposes. ${ }^{14-19}$ Determining hexanal and heptenal content by headspace single-drop microextraction and purge-and-trap GC analysis has also been reported. ${ }^{20,21}$ As a new approach for the evaluation of lipid oxidation, dynamic headspace analysis has been studied for the determination of volatile compounds originating from several foods, including soybean oil, meats, fish, and fruits. ${ }^{22-27}$ In this research we validated the automated dynamic headspace (auto-DHS) method for the analysis of hexanal in vegetable oils after storage at several different temperatures. The AV, POV and fatty acid change were determined to evaluate the lipid oxidation and to evaluate the correlations between these parameters and hexanal concentration. The auto-DHS sampler coupled to a mass spectrometer was employed to determine hexanal content in vegetable oils as an oxidative marker during storage. 


\section{Experimental}

\section{Materials and reagents}

Soybean oil, corn oil and olive oil were purchased from a local retail store in Seongnam city, Gyeonggi province, Republic of Korea. On receipt, the air in the headspace of sample bottle was replaced with nitrogen to protect the oil from air. The oils were stored in dark-glass bottles below $4^{\circ} \mathrm{C}$ in an airtight container prior to analysis. For each oil, $200 \mathrm{~mL}$ was put in a 250 -mL glass bottle, which was placed in a dry oven for 56 days at 25,80 and $105^{\circ} \mathrm{C}$ to accelerate the oxidation. Hexanal was purchased from Sigma (St. Louis, MO). A standard stock solution containing $100 \mu \mathrm{g} \mathrm{mL}^{-1}$ hexanal was prepared in ethanol and stored at $-20^{\circ} \mathrm{C}$. Individual reference fatty acid methyl ester (FAME) standards of fatty acid were purchased from Nu-Chek Prep Inc. (Elysian, MN). Other solvents and reagent used in this work were all of analytical grade.

\section{Sample preparation}

A 200-mg sample of each oil was weighed into a standard $20 \mathrm{~mL}$ screw cap vial (silicone layer/PTFE lamination, Gerstel, Müllheim a/d Ruhr, Germany). Spiking solutions were prepared by diluting the stock solution with appropriate volumes of soybean oil to generate resulting concentrations of $10,25,50$, 100,500 and $1000 \mathrm{ng} \mathrm{mL}^{-1}$ for calibration. The methyl ester of the fatty acid was obtained by the esterification reaction in a Techne DB-3D heating block (Barloworld Scientific US Ltd., Burlington, $\mathrm{NJ}$ ) with $\mathrm{BF}_{3}$ as a catalyst. The acid value (AV) and the peroxide value (POV) were determined according to the AOAC method. ${ }^{6}$

\section{Chromatography}

All analyses were performed on an Agilent 6890 GC system, coupled to an Agilent MD 5973 quadruple mass spectrometer. Compounds were separated by using a 5\% phenyl-methyl silicone fused-silica capillary column (DB-5, $60 \mathrm{~m}$ in length, $0.25 \mu \mathrm{m}$ i.d., $0.25 \mu \mathrm{m}$ film thickness, J \& W Scientific Inc., Folsom, CA). The carrier gas was helium with a flow rate of $1.1 \mathrm{~mL} \mathrm{~min}^{-1}$. The splitless mode was used. The injector temperature was set as $250^{\circ} \mathrm{C}$. The column temperature programs were the following: initial temperature of $50^{\circ} \mathrm{C}$ (hold $1 \mathrm{~min}$ ), increase to $240^{\circ} \mathrm{C}$ at the ramping rate of $10^{\circ} \mathrm{C} \mathrm{min}^{-1}$, hold for $5.0 \mathrm{~min}$. The quadrupole temperature, transfer line temperature and MS source temperature were 150, 280 and $230^{\circ} \mathrm{C}$, respectively. Ions with masses of 41,44 and 56 were selected for the determination and confirmation of hexanal. The instrument was equipped with a CIS-4 programmable temperature vaporizing injector (PTV, Gerstel, Müllheim a/d Ruhr, Germany) with a thermal desorption (TD/PTV, Gerstel) unit for dynamic headspace sampling.

\section{Dynamic headspace sampling}

Sample extraction and introduction were fully automated using a GERSTEL MPS-2 autosampler configured for the auto-DHS injection, which was operated with the GERSTEL MAESTRO software Ver. 3.2. A GERSTEL thermal desorption unit (TDU) was used for thermal desorption of the adsorbent-filled traps in conjunction with the auto-DHS module. After each oil had incubated in the sample bottle for $5 \mathrm{~min}$ at $80^{\circ} \mathrm{C}$, dynamic sampling was performed by connecting a tube to the outlet of the sample bottle and applying a flow of nitrogen at $40 \mathrm{~mL} \mathrm{~min}{ }^{-1}$ for $12 \mathrm{~min}$. Concentration tubes packed with 2,6-diphenylene-oxide polymer resin (Tenax TA 60/80, average pore size $200 \mathrm{~nm}$ ) were purchased from Gerstel. The desorption of the trapped hexanal was carried out for 12.5 min using a Gerstel TDU-2 thermal desorption unit mounted on top of the CIS-4 PTV injector. For all experiments, desorption was in the splitless mode using helium at a flow rate of $150 \mathrm{~mL} \mathrm{~min}^{-1}$. The TDU- 2 was programmed from 40 to $280^{\circ} \mathrm{C}$ at $720^{\circ} \mathrm{C} \mathrm{min}{ }^{-1}$ with a final time of $5 \mathrm{~min}$. To quantitatively trap the hexanal released from the TDU and to guarantee small initial injection bands, we cooled the PTV to $-60^{\circ} \mathrm{C}$ with liquid nitrogen. When the desorption was complete, the PTV was heated from -60 to $270^{\circ} \mathrm{C}$ at $12^{\circ} \mathrm{C} \mathrm{s}^{-1}$ with the split valve closed during operation.

\section{Method validation}

Linearity. The hexanal-free oil was used for the preparation of the calibration solutions. Calibration solutions with concentrations of 10, 25, 50, 100, 500 and $1000 \mathrm{ng} \mathrm{mL}^{-1}$ were prepared by dilution of hexanal with pure soybean oil. The linear range of the proposed method was studied by determining calibration curves for the concentration of interest. The auto-DHS was performed at the optimum conditions. The line of best fit for the relationship between the relative peak areas (obtained by integrating the selected $\mathrm{m} / \mathrm{z}, 56$ chromatogram) and the hexanal concentration was determined by linear regression. Precision and accuracy. The reproducibility of the proposed method was expressed by the relative standard deviation (\% RSD). Analyses of vegetable oils containing hexanal were performed in triplicate.

To evaluate the intra-day precision and accuracy, we extracted quality control (QC) samples $(n=6)$ at low, middle and high concentrations in one batch. For the assay of the inter-day precision and accuracy, three consecutive batches of QC samples were made by the same procedure on three different days. Each day, a new calibration curve was constructed when the samples were extracted. The precision and the accuracy were reported as the relative standard deviation (\% RSD).

Recovery, $L O D$ and $L O Q$. The recovery of hexanal using the standard addition method was calculated as follows:

$$
\text { Recovery } \%=\left[\left(C_{\mathrm{t}}-C_{\mathrm{u}}\right) \cdot C_{\mathrm{a}}^{-1}\right] \times 100
$$

Here $C_{\mathrm{t}}$ is the total concentration of hexanal measured, $C_{\mathrm{u}}$ the concentration of hexanal present in the original soybean oil, and $C_{\mathrm{a}}$ the concentration of the pure hexanal added to the original soybean oil. The detection limit was also determined. The limit of detection (LOD) and limit of quantitation (LOQ) values were estimated at an $\mathrm{SD} / b$ ratio of 3 and 10 , where $\mathrm{SD}$ and $b$ stand for the standard deviation of the intercept and slope of the regression line, respectively. To study the accuracy of the method, we performed recovery experiments using the standard addition method. Triplicate analyses of hexanal-added soybean oil were performed.

\section{Quantification of hexanal in vegetable oils}

Extractions were performed at $80^{\circ} \mathrm{C}$ for $12 \mathrm{~min}$, with the stirring rate of $1500 \mathrm{rpm}$. The extracted hexanal was injected into the GC/MS for analysis. To obtain the calibration curve for quantitative analyses of hexanal, we introduced $200 \mathrm{mg}$ of each calibration solutions in concentrations 10, 25, 50, 100, 500 and $1000 \mathrm{ng} \mathrm{mL}^{-1}$ into $20 \mathrm{~mL}$ headspace vials.

\section{Results and Discussion}

\section{Optimization of chromatography}

Figure 1 shows the extracted ion chromatogram of the volatile compounds including hexanal from the several vegetable oils. 

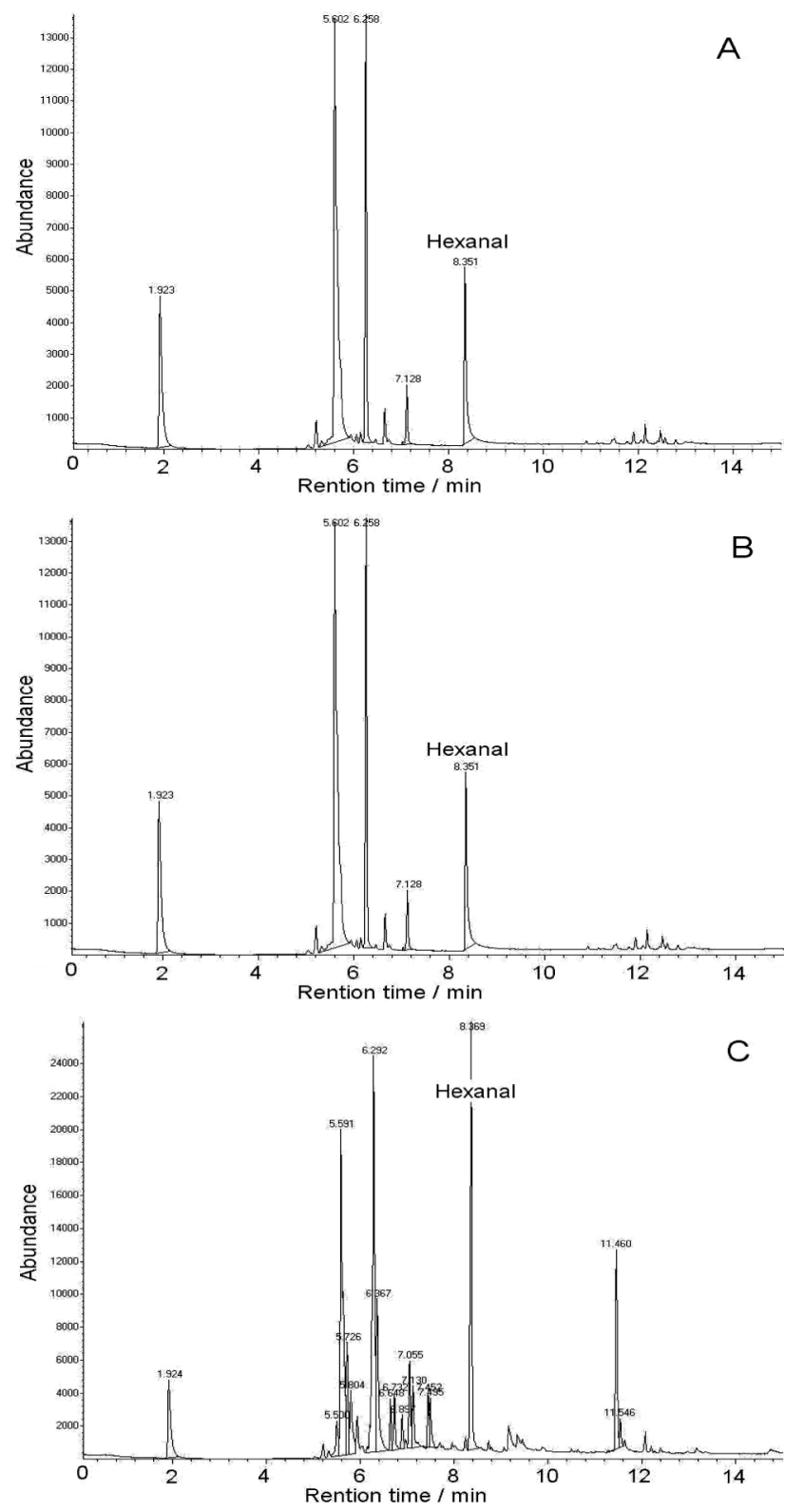

Fig. 1 Typical extracted ion chromatograms of hexanal in several vegetable oils. A, Soybean oil; B, corn oil; C, olive oil.

The hexanal eluted approximately $8.3 \mathrm{~min}$ after injection. To shorten the separation time and to improve the peak symmetry, one should consider several chromatographic parameters, including the column polarity and the oven temperature. It was reported that volatile compounds, including aldehydes and acids, could be separated on the both non-polar and intermediate polar columns. , $10,15,17$ The separation of hexanal from vegetable oils could be successfully performed on a DB- 5 column, which is one of the less polar columns.

\section{Method validation}

Linearity, $L O D$ and $L O Q$. The assay linearity was measured by a weighted least-squares linear regression analysis. The calibration curve of hexanal was $y=3.160 x+71.633\left(r^{2}=\right.$ $0.9999)$ and corresponded to test ranges of $10-1000 \mathrm{ng} \mathrm{mL}^{-1}$. The LOD was $3.3 \mathrm{ng} \mathrm{mL}^{-1}$ and the LOQ was $9.8 \mathrm{ng} \mathrm{mL}^{-1}$.

Precision, accuracy and recovery. The system precision was
Table 1 Intra- and inter-day precision and accuracy data of the DHS-GC/MS method for the determination ${ }^{\mathrm{a}}$ of hexanal in vegetable oils

\begin{tabular}{ccccc}
\hline Component & $\begin{array}{c}\text { Spiked amount/ } \\
\mathrm{ng} \mathrm{mL}^{-1}\end{array}$ & $\begin{array}{c}\text { Intra-day, } \\
\%\end{array}$ & $\begin{array}{c}\text { Inter-day, } \\
\%\end{array}$ & $\begin{array}{c}\text { Recovery, } \\
\%\end{array}$ \\
\hline \multirow{2}{*}{ Hexanal } & 10 & 3.88 & 4.25 & 95.6 \\
& 25 & 1.21 & 3.75 & 94.5 \\
& 50 & 1.85 & 2.65 & 94.2 \\
& 100 & 2.88 & 2.61 & 93.8 \\
& 500 & 3.67 & 3.49 & 94.2 \\
& 1000 & 2.24 & 3.56 & 81.4 \\
\hline
\end{tabular}

a. The sample weight was approximately $200 \mathrm{mg}$ and the concentration of hexanal in the initial sample was approximately $2.4 \mathrm{ng} \mathrm{mL}^{-1}$.

Table 2 Changes in the acid value ${ }^{a, b}$ during storage (mg $\mathrm{KOH} / 1 \mathrm{~g}$ of oil)

\begin{tabular}{ccccccc}
\hline $\begin{array}{c}\text { Storage } \\
\text { temp./ }\end{array}$ & \multicolumn{5}{c}{ Oilc ${ }^{\circ} \mathrm{C}$} \\
\cline { 3 - 7 } & & 0 & 14 & 28 & 42 & 56 \\
\hline 25 & SB & $0.03 \pm 0.01$ & $0.02 \pm 0.01$ & $0.06 \pm 0.00$ & $0.06 \pm 0.02$ & $0.01 \pm 0.01$ \\
& CR & $0.08 \pm 0.00$ & $0.06 \pm 0.03$ & $0.09 \pm 0.01$ & $0.08 \pm 0.02$ & $0.08 \pm 0.01$ \\
& OL & $0.66 \pm 0.00$ & $0.55 \pm 0.00$ & $0.65 \pm 0.05$ & $0.64 \pm 0.03$ & $0.67 \pm 0.00$ \\
80 & SB & $0.03 \pm 0.01$ & $0.06 \pm 0.00$ & $0.18 \pm 0.02$ & $0.28 \pm 0.02$ & $0.57 \pm 0.01$ \\
& CR & $0.08 \pm 0.00$ & $0.12 \pm 0.03$ & $0.18 \pm 0.01$ & $0.27 \pm 0.00$ & $0.49 \pm 0.01$ \\
& OL & $0.66 \pm 0.00$ & $0.66 \pm 0.00$ & $0.75 \pm 0.01$ & $0.98 \pm 0.04$ & $1.55 \pm 0.06$ \\
105 & SB & $0.03 \pm 0.01$ & $0.08 \pm 0.03$ & $0.20 \pm 0.02$ & $0.25 \pm 0.01$ & $0.48 \pm 0.00$ \\
& CR & $0.08 \pm 0.00$ & $0.13 \pm 0.01$ & $0.32 \pm 0.01$ & $0.55 \pm 0.03$ & $2.07 \pm 0.05$ \\
& OL & $0.66 \pm 0.00$ & $0.53 \pm 0.18$ & $0.88 \pm 0.00$ & $1.43 \pm 0.06$ & $2.42 \pm 0.01$ \\
\hline
\end{tabular}

a. Free fatty acid as oleic acid.

b. Values represent the means of triplicate analysis \pm SD.

c. SB, soybean oil; CR, corn oil; OL, olive oil.

evaluated by the precision of the retention time and the peak area of hexanal at the six levels of hexanal concentrations. The precision of retention time and peak area were no more than 1 and 3\%, respectively (data not shown). The results indicated that the system precision was good enough, although the temperature programming of the column oven was used.

The precision of intra- and inter-day were no more than 3.88 and $4.25 \%$, respectively (Table 1 ). The recoveries were also evaluated by comparing the peak area of the target compounds of samples to those of the spiked in post-extracts at the same concentrations. The mean recoveries ranged from 81.4 to $95.6 \%$ depending on the different concentrations.

\section{Changes of AV, POV and fatty acid compositions}

The changes of AV, POV and fatty acid composition as quality factors during storage at 25,80 and $105^{\circ} \mathrm{C}$ are shown in Table 2, Table 3 and Table 4, respectively. A slow increase in the AV was observed in the oil stored at $25^{\circ} \mathrm{C}$; however, a significant increase in the $\mathrm{AV}$ was observed in the oils stored at 80 and $105^{\circ} \mathrm{C}$. The $\mathrm{AV}$ of olive oil was the highest and changed the fastest of the three vegetable oils tested. The AV of olive oil changed faster because the extra virgin olive oil was rich in lipase. The peroxide value of the three vegetable oils showed a similar trend in the acid value. However, the POV of the oils stored at $80^{\circ} \mathrm{C}$ was higher than that in oils stored at $105^{\circ} \mathrm{C}$. It is generally known that the POV would decrease after reaching the maximum value during storage and could not be used as the marker of lipid oxidation at extended storage times. Therefore, 
Table 3 Changes in the peroxide value ${ }^{\mathrm{a}, \mathrm{b}}$ during storage

\begin{tabular}{|c|c|c|c|c|c|c|}
\hline \multirow{2}{*}{$\begin{array}{l}\text { Storage temp./ } \\
{ }^{\circ} \mathrm{C}\end{array}$} & \multirow{2}{*}{$\mathrm{Oil}^{\mathrm{c}}$} & \multicolumn{5}{|c|}{ Days of storage } \\
\hline & & 0 & 14 & 28 & 42 & 56 \\
\hline \multirow[t]{3}{*}{25} & SB & $1.4 \pm 0.28$ & $4.0 \pm 0.25$ & $5.8 \pm 0.29$ & $13.2 \pm 2.05$ & $14.4 \pm 1.05$ \\
\hline & CR & $1.1 \pm 0.12$ & $3.2 \pm 0.28$ & $3.9 \pm 0.11$ & $9.8 \pm 2.00$ & $9.8 \pm 0.70$ \\
\hline & $\mathrm{OL}$ & $7.3 \pm 1.81$ & $22.2 \pm 0.40$ & $28.6 \pm 0.88$ & $45.2 \pm 4.84$ & $57.7 \pm 1.49$ \\
\hline \multirow[t]{3}{*}{80} & $\mathrm{SB}$ & $1.4 \pm 0.28$ & $36.2 \pm 0.82$ & $73.4 \pm 4.03$ & $93.0 \pm 8.71$ & $132.0 \pm 0.92$ \\
\hline & CR & $1.1 \pm 0.12$ & $34.2 \pm 0.30$ & $82.1 \pm 3.76$ & $104.9 \pm 12.52$ & $146.3 \pm 1.91$ \\
\hline & $\mathrm{OL}$ & $7.3 \pm 5.81$ & $30.2 \pm 0.45$ & $50.8 \pm 3.50$ & $86.5 \pm 5.51$ & $131.6 \pm 0.16$ \\
\hline \multirow[t]{3}{*}{105} & SB & $1.4 \pm 0.28$ & $12.5 \pm 0.17$ & $20.0 \pm 1.27$ & $24.8 \pm 3.68$ & $36.6 \pm 1.36$ \\
\hline & CR & $1.1 \pm 0.12$ & $16.6 \pm 0.36$ & $25.9 \pm 4.85$ & $34.3 \pm 6.08$ & $104.1 \pm 0.71$ \\
\hline & $\mathrm{OL}$ & $7.3 \pm 5.81$ & $16.7 \pm 0.36$ & $44.0 \pm 5.02$ & $44.1 \pm 1.45$ & $44.8 \pm 1.96$ \\
\hline
\end{tabular}

a. $\mathrm{mEq}$ of $\mathrm{O}_{2} \mathrm{~kg}^{-1}$ of oil. b. Values represent the means of triplicate analysis \pm SD. c. SB, soybean oil; CR, corn oil; OL, olive oil.

Table 4 Changes in the fatty acid compositions ${ }^{\text {a }}$ during storage

\begin{tabular}{|c|c|c|c|c|c|c|c|c|}
\hline \multirow{2}{*}{$\begin{array}{l}\text { Storage temp./ } \\
{ }^{\circ} \mathrm{C}\end{array}$} & \multirow{2}{*}{$\mathrm{Oil}^{\mathrm{b}}$} & \multirow{2}{*}{ Period } & \multicolumn{6}{|c|}{ Fatty acid compositions, $\%$} \\
\hline & & & $\mathrm{C} 16: 0$ & C18:0 & $\mathrm{C} 18: \ln 9 \mathrm{t}^{\mathrm{c}}$ & $\mathrm{C} 18: \ln 9 \mathrm{c}^{\mathrm{d}}$ & $\mathrm{C} 18: 2 \mathrm{n} 6 \mathrm{c}^{\mathrm{d}}$ & $\mathrm{C} 18: 3 \mathrm{n} 3 \mathrm{c}^{\mathrm{d}}$ \\
\hline \multirow[t]{15}{*}{25} & \multirow[t]{5}{*}{$\mathrm{SB}$} & 0 & 10.47 & 4.14 & 0.05 & 21.93 & 52.26 & 6.14 \\
\hline & & 14 & 10.50 & 4.14 & 0.05 & 21.97 & 52.16 & 6.14 \\
\hline & & 28 & 10.50 & 4.14 & 0.05 & 21.90 & 52.12 & 6.19 \\
\hline & & 42 & 10.53 & 4.16 & 0.05 & 21.95 & 52.08 & 6.23 \\
\hline & & 56 & 10.57 & 4.17 & 0.05 & 21.94 & 52.04 & 6.23 \\
\hline & \multirow[t]{5}{*}{$\mathrm{CR}$} & 0 & 10.71 & 1.92 & 0.05 & 27.06 & 54.07 & 1.21 \\
\hline & & 14 & 10.86 & 1.93 & 0.05 & 27.03 & 53.93 & 1.21 \\
\hline & & 28 & 10.85 & 1.95 & 0.05 & 26.97 & 53.96 & 1.24 \\
\hline & & 42 & 10.93 & 1.97 & 0.05 & 27.08 & 53.75 & 1.24 \\
\hline & & 56 & 10.96 & 1.97 & 0.05 & 27.02 & 53.78 & 1.24 \\
\hline & \multirow[t]{5}{*}{ OL } & 0 & 10.19 & 3.64 & 0.07 & 75.64 & 4.80 & 0.67 \\
\hline & & 14 & 10.26 & 3.64 & 0.06 & 75.58 & 4.79 & 0.67 \\
\hline & & 28 & 10.36 & 3.67 & 0.07 & 75.47 & 4.78 & 0.66 \\
\hline & & 42 & 10.33 & 3.70 & 0.07 & 75.59 & 4.85 & 0.67 \\
\hline & & 56 & 10.38 & 3.82 & 0.08 & 75.64 & 4.80 & 0.67 \\
\hline \multirow[t]{15}{*}{80} & \multirow[t]{5}{*}{$\mathrm{SB}$} & 0 & 10.47 & 4.14 & 0.05 & 21.93 & 52.26 & 6.14 \\
\hline & & 14 & 10.59 & 4.18 & 0.05 & 22.12 & 52.01 & 6.05 \\
\hline & & 28 & 10.74 & 4.25 & 0.06 & 22.47 & 51.59 & 5.89 \\
\hline & & 42 & 11.11 & 4.41 & 0.06 & 22.90 & 50.88 & 5.65 \\
\hline & & 56 & 11.75 & 4.45 & 0.07 & 23.21 & 51.26 & 5.01 \\
\hline & \multirow[t]{5}{*}{$\mathrm{CR}$} & 0 & 10.71 & 1.92 & 0.05 & 27.06 & 54.07 & 1.21 \\
\hline & & 14 & 10.92 & 1.96 & 0.04 & 27.22 & 53.68 & 1.18 \\
\hline & & 28 & 11.06 & 2.00 & 0.07 & 27.51 & 53.21 & 1.15 \\
\hline & & 42 & 11.37 & 2.06 & 0.06 & 28.05 & 52.35 & 1.09 \\
\hline & & 56 & 11.75 & 2.12 & 0.07 & 28.81 & 51.26 & 1.01 \\
\hline & \multirow[t]{5}{*}{ OL } & 0 & 10.19 & 3.64 & 0.07 & 75.64 & 4.80 & 0.67 \\
\hline & & 14 & 10.32 & 3.68 & 0.07 & 75.77 & 4.57 & 0.60 \\
\hline & & 28 & 10.30 & 3.71 & 0.07 & 76.04 & 4.39 & 0.51 \\
\hline & & 42 & 10.64 & 3.81 & 0.07 & 76.11 & 3.98 & 0.39 \\
\hline & & 56 & 10.77 & 3.88 & 0.07 & 76.33 & 3.65 & 0.30 \\
\hline \multirow[t]{15}{*}{105} & \multirow[t]{5}{*}{$\mathrm{SB}$} & 0 & 10.47 & 4.14 & 0.05 & 21.93 & 52.26 & 6.14 \\
\hline & & 14 & 10.69 & 4.21 & 0.05 & 22.16 & 51.86 & 6.03 \\
\hline & & 28 & 10.74 & 4.30 & 0.07 & 22.52 & 51.52 & 5.84 \\
\hline & & 42 & 11.26 & 4.45 & 0.06 & 23.04 & 50.64 & 5.58 \\
\hline & & 56 & 11.69 & 4.65 & 0.08 & 23.84 & 49.62 & 5.15 \\
\hline & \multirow[t]{5}{*}{$\mathrm{CR}$} & 0 & 10.71 & 1.92 & 0.05 & 27.06 & 54.07 & 1.21 \\
\hline & & 14 & 10.94 & 1.96 & 0.05 & 27.44 & 53.45 & 1.16 \\
\hline & & 28 & 11.30 & 2.01 & 0.06 & 27.90 & 52.64 & 1.09 \\
\hline & & 42 & 11.85 & 2.13 & 0.07 & 28.64 & 51.30 & 1.02 \\
\hline & & 56 & 12.17 & 2.55 & 0.10 & 32.70 & 44.84 & 0.65 \\
\hline & \multirow[t]{5}{*}{$\mathrm{OL}$} & 0 & 10.19 & 3.64 & 0.07 & 75.64 & 4.80 & 0.67 \\
\hline & & 14 & 10.40 & 3.72 & 0.09 & 75.91 & 4.38 & 0.50 \\
\hline & & 28 & 10.53 & 3.76 & 0.09 & 76.10 & 4.09 & 0.43 \\
\hline & & 42 & 11.14 & 3.98 & 0.11 & 76.27 & 3.28 & 0.22 \\
\hline & & 56 & 11.82 & 4.24 & 0.14 & 76.37 & 2.34 & 0.10 \\
\hline
\end{tabular}

a. Values represent the means of duplicate analysis. b. SB, soybean oil; CR, corn oil; OL, olive oil. c. trans form of fatty acid. d. cis form of fatty acid. 
Table 5 Changes in the hexanal ${ }^{\mathrm{a}}$ content during storage $\left(\mathrm{ng} \mathrm{mL}^{-1}\right)$

\begin{tabular}{ccccccc}
\hline \multirow{2}{*}{$\begin{array}{c}\text { Storage temp./ } \\
{ }^{\circ} \mathrm{C}\end{array}$} & Oib $^{\mathrm{b}}$ & \multicolumn{5}{c}{ Days of storage } \\
\cline { 3 - 7 } & & 0 & 14 & 28 & 42 & 56 \\
\hline \multirow{2}{*}{25} & SB & $114 \pm 40$ & $127 \pm 15$ & $183 \pm 21$ & $194 \pm 30$ & $263 \pm 25$ \\
& CR & $161 \pm 35$ & $263 \pm 40$ & $278 \pm 13$ & $379 \pm 18$ & $478 \pm 6$ \\
& OL & $1443 \pm 134$ & $1055 \pm 88$ & $1071 \pm 82$ & $1093 \pm 11$ & $1207 \pm 138$ \\
80 & SB & $114 \pm 40$ & $2922 \pm 223$ & $6196 \pm 786$ & $10702 \pm 689$ & $17178 \pm 2829$ \\
& CR & $161 \pm 35$ & $3523 \pm 235$ & $6905 \pm 212$ & $10962 \pm 746$ & $20321 \pm 1471$ \\
& OL & $1443 \pm 134$ & $4334 \pm 212$ & $8628 \pm 697$ & $12877 \pm 1322$ & $21798 \pm 1610$ \\
& SB & $114 \pm 40$ & $5042 \pm 412$ & $5518 \pm 660$ & $6073 \pm 562$ & $9444 \pm 889$ \\
& CR & $161 \pm 35$ & $5793 \pm 344$ & $6824 \pm 660$ & $11609 \pm 575$ & $39302 \pm 3144$ \\
& OL & $1443 \pm 134$ & $4677 \pm 174$ & $8106 \pm 1404$ & $8508 \pm 329$ & $10162 \pm 124$ \\
\hline
\end{tabular}

a. Values represent the means of triplicate analysis \pm SD. b. SB, soybean oil; CR, corn oil; OL, olive oil.

we investigated the change in fatty acid composition as another marker of lipid oxidation during storage. The results showed that no significant change of fatty acid composition occurred during storage at $25^{\circ} \mathrm{C}$ for 8 weeks. However, when the oils were stored at $80^{\circ} \mathrm{C}$, the ratio of palmitic and stearic acids to total fatty acids was not changed. The ratio of oleic acid to total fatty acids increased during storage, and the ratio of linoleic and linolenic acids to total fatty acids decreased during the storage.

A similar trend was found in the oils stored at $105^{\circ} \mathrm{C}$ for 8 weeks. The concentration of $\mathrm{C} 18$ with one double bond trans fat was increased with increased time. However, the ratios of linoleic and linolenic acids to the total fatty acid decreased similarly to the ratios of the oils stored at $80^{\circ} \mathrm{C}$. It seemed that the high unsaturated fatty acid could be broken down easily to produce the short chain volatile compounds by the lipid oxidation.

\section{Changes in hexanal concentration}

The changes of hexanal concentration during storage are reported in Table 5. The hexanal concentration in vegetable oils increased constantly in the all storage temperatures as a function of storage time.

Corn oil consists of approximately $25 \%$ oleic acid and $60 \%$ linoleic acid; it thus contains the highest unsaturated fatty acid among the three oils. Hexanal is formed by the oxidation of linoleic acid by the hemolytic $\beta$-scission of 13-hydroperoxyoctadeca-9,11-dienoic acid via 13-peroxide during storage at 80 and $105^{\circ} \mathrm{C}$. Therefore, the hexanal concentration in corn oil is much higher than those in soybean and olive oils. In the meantime, the increase of hexanal concentration in the oils stored at $25^{\circ} \mathrm{C}$ was small in all oils; however, the increase of hexanal concentration at 80 and $105^{\circ} \mathrm{C}$ was large. It was not so clear why the hexanal concentration in oils stored at $105^{\circ} \mathrm{C}$ was lower than that in stored at $105^{\circ} \mathrm{C}$. However, it seemed that the hexanal was released to the headspace of bottle after formation during storage at $105^{\circ} \mathrm{C}$ due to its volatility in high temperature. Jelen et al. analyzed the volatile compounds in rapeseed oil using SPME; they report that volatile compounds concentration including hexanal sharply increased during 10 days of storage at $60^{\circ}$ C. $^{7}$ Garcia-Llatas et al. also monitored the hexanal concentration in lipid foods including infant formulas with long chain polyunsaturated fatty acids added, revealing that the hexanal concentration in 7 month storage was lower than that in 4 month storage. Such results showed the similar trend to those obtained from our experiments. ${ }^{10,11,19}$
Table 6 Correlation coefficient, $R$, between hexanal and other oxidative markers

\begin{tabular}{ccrrrr}
\hline $\begin{array}{c}\text { Storage } \\
\text { temp. } /^{\circ} \mathrm{C}\end{array}$ & Oil $^{\mathrm{a}}$ & AV-Hx & POV-Hx & SF\&O ${ }^{\mathrm{b}}-\mathrm{Hx}$ & PUFA $^{\mathrm{b}}-\mathrm{Hx}$ \\
\hline \multirow{2}{*}{25} & SB & -0.0923 & 0.9065 & 0.4963 & -0.4557 \\
& CR & 0.1205 & 0.9491 & 0.9143 & -0.9091 \\
& OL & 0.5134 & -0.4194 & 0.1245 & 0.1194 \\
80 & SB & 0.9850 & 0.9785 & 0.9428 & -0.9422 \\
& CR & 0.9943 & 0.9651 & 0.9953 & -0.9950 \\
& OL & 0.9624 & 0.9961 & 0.9861 & -0.9856 \\
105 & SB & 0.8978 & 0.9767 & 0.8892 & -0.8881 \\
& CR & 0.9940 & 0.9972 & 0.9966 & -0.9967 \\
& OL & 0.7759 & 0.9669 & 0.8923 & -0.8926 \\
\hline
\end{tabular}

a. SB, soybean oil; CR, corn oil; OL, olive oil.

b. Hx, hexanal; SF\&O, saturated fat and oleic acid; PUFA, polyunsaturated fatty acid.

Correlation coefficient $R$ between hexanal and other oxidative indicators

Regarding the possibility of hexanal concentration determined by the auto-DHS GC/MS as an oxidative indicator, the correlation coefficient, $R$, between hexanal and other oxidative indicators was calculated as shown in Table 6 . The results showed that the hexanal concentration had poor correlation coefficients with AV, POV, saturated fat and oleic acids (SF\&O), and polyunsaturated fatty acid (PUFA) in the oils stored at $25^{\circ} \mathrm{C}$. It seems that the storage temperature below $25^{\circ} \mathrm{C}$ may not affect the oxidation of vegetable oil significantly. In addition to the changes of $\mathrm{AV}$ and POV, we found that the hexanal concentration obtained by the auto-DHS-GC/MS method was not an appropriate indicator for the lipid oxidation when the oils were stored at $25^{\circ} \mathrm{C}$. The $R$ value between hexanal and other oxidative indicators, including $\mathrm{AV}, \mathrm{POV}$ and fatty acid composition, was good for the oils stored at 80 and $105^{\circ} \mathrm{C}$, revealing that hexanal can be used as the oxidative marker of vegetable oils.

\section{Conclusion}

The auto-DHS technique is a sensitive method that can be utilized to extract aldehyde compounds that are produced due to lipid oxidation. The auto-DHS technique is also a rapid method that can be utilized to indicate lipid oxidation or food shelf-life stability by determining the concentration of hexanal using a 
gas chromatograph/mass spectrometer. Hexanal proved to be a reliable indicator for assessing the degree of oxidation of vegetable oils.

\section{Acknowledgements}

This research was financially supported by the Research Foundation of Korea (No. F01-2009-000-10024-0), the Korea Food Research Institute (N01207, ER102000) and the National Nature Scientific Foundation of China-Korea Joint Research Project (No. 20911140274). We deeply appreciate their supports.

\section{References}

1. H. H. F. Refsgaard, L. Tsai, and E. R. Stadtman, Biochemistry, 2000, 97, 611.

2. J. M. Olias, A. G. Perez, J. J. Rios, and L. C. Sanz, J. Agric. Food Chem., 1993, 41, 2368.

3. A. Hatanaka, T. Kajiwara, J. Sekiya, M. Imoto, and S. Inuoye, Plant Cell Physiol., 1982, 23, 91.

4. A. Hatanaka, J. Sekiya, and T. Kajiwara, J. Agric. Food Chem., 1983, 31, 176.

5. M. A. Al-Rowaily, Pak. J. Nutr., 2008, 7, 118.

6. W. Horwitz and G. W. Latimer, Jr., "Official Methods of Analysis", 18th ed., 2005, AOAC INT., Gaithersburg, MD, Method 965.33/920.161.

7. H. H. Jelen, M. Obuchowska, R. Zawirska-Wojtasiak, and E. Wasowicz, J. Agric. Food Chem., 2000, 48, 2360.

8. B. Plutowska and W. Wardencki, Food Chem., 2007, 101, 845 .

9. B. Berlioz, C. Cordella, J. Cavalli, L. Lizzani-Cuvelier, A. Loiseau, and X. Fernandez, J. Agric. Food Chem., 2006, 54, 10092.

10. G. Garcia-Llatas, M. J. Lagarda, F. Romero, P. Abellan, and
R. Farre, Food Chem., 2006, 101, 1078.

11. C. M. Kalua, M. S. Allen, D. R. Bedgood Jr., A. G. Bishop, P. D. Prenzler, and K. Robards, Food Chem., 2007, 100, 273.

12. A. J. St. Angelo, J. R. Vercellotti, M. G. Legendre, C. H. Vinneit, J. W. Kuan, C. James Jr., and H. P. Dupuy, J. Food Sci., 1987, 52, 1163 .

13. F. Ulberth and D. Roubicek, Food Chem., 1993, 46, 137.

14. C. Bicchi, C. Cordero, E. Liberto, P. Rubiolo, and B. Sgorbini, J. Chromatogr., A, 2004, 1024, 217.

15. B. Jaillais, V. Bertrand, and J. Auger, Talanta, 1999, 48, 747.

16. B. Jaillais, F. Cadoux, and J. Auger, Talanta, 1999, 50, 423.

17. E. Sanchez-Palomo, M. Consuelo Diaz-Maroto, and M. Soledad Perez-Coello, Talanta, 2005, 66, 1152.

18. F. Giuffrida, P. Golay, F. Destaillats, B. Hug, and F. Dionisi, Eur. J. Lipid Sci. Technol., 2005, 107, 792.

19. L. N. Fernando, E. P. Berg, and I. U. Grun, J. Food Compos. Anal., 2003, 16, 179.

20. N. Li, C. Deng, N. Yao, X. Shen, and X. Zhang, Anal. Chim. Acta, 2005, 540, 317.

21. D. U. Ahn, C. Jo, and D. G. Olson, J. Agric. Food Chem., 1999, 47, 2776.

22. E. Selke and E. N. Frankel, J. Am. Oil Chem. Soc., 1987, 64, 749.

23. K. C. Nam, J. Cordray, and D. U. Ahn, Iowa State University Animal Industry Report, 2005.

24. T. Aro, R. Tahvonen, L. Koskinen, and H. Kallio, Eur. Food Res. Technol., 2003, 216, 483.

25. M. G. Moshonas and P. E. Shaw, J. Agric. Food Chem., 1994, 42, 1525.

26. J. Vercammen, P. Sandra, E. Baltussen, T. Sandra, and F. David, J. High Resolut. Chromatogr., 2000, 23, 547.

27. O. Lerch and C. Gil, Gerstel Appnote 3/2008, "Determination of Aldehydes and Ketones in Oily Matrices Using a Novel Dynamic Headspace Sampler Coupled to GC/MS", 2008, Gerstel GmbH \& Co. KG, Germany. 